\title{
A Mobilidade e o Ciberespaço: Explorando e interagindo nas cidades contemporâneas
}

The mobility and the cyberspace: exploring and interacting in the contemporary cities

por Alice T. C. Pereira, Erik Silva Dos Santos, Eugenio A. D. Merino, Gilson Braviano e Lucas Franco Colusso

\section{RESUMO}

$\mathrm{Na}$ análise das formas de interação dos cidadãos com as metrópoles contemporâneas, questionando se cidades e cidadãos estão efetivamente imersos no ciberespaço, este trabalho enfoca a participação popular com dispositivos móveis e as novas realidades de interação. Descrevem-se as mudanças na comunicação, a complexidade das cidades modernas e o novo cidadão móvel. Apresentam-se resultados iniciais de uma pesquisa que corrobora as teorias da interação no ciberespaço e nas cidades, através da mobilidade, finalizando com uma análise de possibilidades e limites criados nesta nova era de mobilidade.

Palavras-chave mobilidade; ciberespaço; cidades contemporâneas

\begin{abstract}
In the analysis of the ways citizens interact with the contemporary metropolis, questioning whether cities and citizens are effectively immersed in cyberspace, this work focuses on popular participation with mobile devices and the new realities of interaction. It describes the changes in communication, the complexity of modern cities and the new mobile citizen. We present initial results of a study that supports the theories of interaction in cyberspace and in cities through mobility, ending with an analysis of possibilities and limitations created in this new era of mobility.
\end{abstract}

Keywords mobility; cyberspace; contemporary cities 


\section{Introdução}

Viver em grandes cidades contemporâneas muda fundamentalmente a forma como as pessoas se comunicam umas com as outras, e os desenvolvimentos tecnológicos têm multiplicado os nossos padrões de comunicação nas últimas décadas tendo, atualmente, nos dispositivos móveis e sem fio uma comunicação em tempo real, conectando informações ao lugar em que estamos contornando a antiga necessidade de mediadores (MÁXIM0, 2010; CASTELLS, 2007). IsSo amplia a participação em uma dimensão espacial e temporal e alarga o leque de possibilidades para o governo e as indústrias, em planejamento urbano, cultural, serviços e ao design aplicado nestas áreas. Novas formas de comunicação urbana móvel estão evoluindo, sendo que nunca antes na história as pessoas tiveram a capacidade de colaboração ao coletar, analisar e publicar informações em escala tão grande e se tornarem atores dos processos de comunicação das cidades As vantagens da comunicação móvel são, segundo Castells (2007): (1) espontaneidade da comunicação in sitio; (2) contato direto entre as pessoas; (3) multimodalidade (voz, texto, imagens, vídeo); (4) interação em tempo real; e (5) conectividade ubíqua.

A telefonia móvel é um dos mercados de comunicação que mais crescem no mundo (GOOGLE et al., 2010). A relevância e o potencial das tecnologias móveis no planejamento urbano e na cultura urbana devem ser pesquisados e desenvolvidos, pois as tecnologias e as ferramentas serão onipresentes e mudarão o comportamento social, como Shirky pontua:

A invenção de uma ferramenta não cria a mudança, ela tem que estar presente o tempo suficiente para que a maioria da sociedade a utilize. É quando uma tecnologia se torna normal, depois onipresente, e, finalmente, tão pervasiva que se torne invisivel, que as mudanças realmente profundas acontecem. (SHIRKY, 2008, p. 105).

Consequentemente, a alta penetração dos smartphones e telefones celulares oferecem oportunidade para um maior envolvimento dos cidadãos em vários aspectos das cidades e das sociedades. A proliferação dos dispositivos móveis pode ser avaliada sob a ótica das redes (CASTELLS, 2009 apud SILVA, 2011) apontando a conexão dos dispositivos em rede como promotora da comunicação ubíqua. Essa crescente forma de comunicação modifica o comportamento info-comunicacional, colocando o indivíduo como elemento central em detrimento da tecnologia. A Era da Informação tem mostrado que a sociedade está ligada mundialmente através das redes e isso implica diretamente em pessoas mais sociáveis, integradas e colaborativas. Na prática, as tecnologias modernas e o ciberespaço são onipresentes na vida das cidades contemporâneas? Os cidadãos e as cidades estão efetivamente conectados a ponto de imergir neste cenário?

Neste artigo, apresenta-se uma pesquisa de caráter exploratório, que baseada em um levantamento bibliográfico busca os conceitos direcionados à integração dos cidadãos para com as metrópoles, ao mesmo tempo em que analisa a importância da tecnologia 
nas relações sociais modernas - em paralelo a isso, aplicou-se um questionário hospedado em plataforma on-line a fim de entender, de que forma as pessoas utilizam dispositivos móveis, com que frequência os utilizam, o propósito do uso e qual a sua opinião a respeito da contribuição destes para a interação entre os cidadãos e o ciberespaço; busca-se investigar, como os dispositivos podem agregar novos valores às cidades, no âmbito da melhoria da qualidade de vida em meio a essa nova forma de comunicação inserida na cultura rápida. 0 texto traz uma investigação do caso das teorias aplicadas ao cotidiano das grandes cidades modernas, fazendo uso de um método hipotético-dedutivo, partindo da problemática de que o desenvolvimento da tecnologia móvel tem formado uma nova forma de interação entre os cidadãos e deduzindo que os dispositivos móveis funcionam como agentes de integração social. Através de meios comparativos, analisa-se o comportamento e a forma de utilização de dispositivos móveis em grandes cidades no Brasil e no mundo.

\section{Ciberespaço e a sociedade contemporânea}

0 ciberespaço é um universo que engendra processos e formas sociais que contribuem para a compreensão da dinâmica social característica da contemporaneidade e pode ser pensado como dimensão constitutiva das sociedades complexas caracterizadas por um intenso processo de interação entre segmentos diferenciados e por grande mobilidade material e simbólica (MÁXIMO, 2010). Afastamo-nos da tendência que traz o uso da palavra "virtual", ao produzir o entendimento que a não presença dos atores físicos possa significar interações não-reais, pois o virtual não se opõe ao real, como diz Lévy (1996 p. 16): “Virtual não é o que não existe, mas o que existe em potência e que tende a atualizar-se, a se resolver."

A internet configura-se como uma rede ou como um conjunto de redes, onde computadores estão instantaneamente ligados através de telefone, satélite, rádio, cabos e outros meios - esse conglomerado de redes em escala mundial amplia expansivamente a possibilidade de acesso à conteúdo para conhecimento ou entretenimento.

Essa rede não limita seus usuários apenas à absorção de informação, ela possibilita a alternativa de desenvolver seu próprio conteúdo e este será útil para si ou para um grupo de pessoas que possuem interesses afins. 0 que ocorre nessa situação é que o acesso à rede, além de gerar informação, funciona como um elo social entre os usuários que a utilizam. Estes usuários, enquanto seres atuantes na rede têm seus motivos para nela habitar. Economia de tempo, entretenimento, independência, autoafirmação, conveniência, experiência e acesso rápido a informação são palavras-chave que motivam as pessoas a serem utilizadoras de dispositivos móveis. A capacidade de fazer as coisas a qualquer momento e de qualquer lugar torna esta experiência um reforçador diário - seja para verificar o saldo da conta bancária, verificar o melhor caminho para chegar a um destino específico ou até mesmo para comprar produtos e serviços, evitando deslocamento e tempo 
em filas. Algumas tendências principais podem ser citadas, que têm melhorado os processos de comunicação nas cidades como nunca ocorreu antes na história (CASTELLS, 2009, apud SILVA, 2011).

A vida social contemporânea é composta por uma multiplicidade de esferas sociais que tendem a ser transitórias, circunstanciais e enraizadas no presente, mas cujo grau de intensidade e permanência varia de acordo com a qualidade dos laços sociais construídos durante as interações, como exemplificam os encontros que ocorrem na e pela internet, que permite que as redes exerçam toda sua flexibilidade e adaptabilidade em favor de decisões descentralizadas, de maior liberdade de expressão, enfim, de uma comunicação global e horizontal (Máximo apud Castells, 2010 , p. 41). A Internet possibilita a coordenação de atividades sociais sem a mediação do lugar, por um lado parece que tudo e todos estão ao alcance de um clique no mouse e por outro, a separação do tempo em relação ao espaço possibilita agirmos localmente num espaço e tempo globais. Trata-se de um meio verdadeiramente interativo, que subverteu a ordem tradicional dos meios de comunicação, as pessoas participam da produção de conteúdos online, publicam suas ideias em blogs, compartilham vídeos e fotos, e se conectam uns com os outros usando redes sociais: A comunicação de "muitos para muitos" se estabelece, o que terá consequências em longo prazo (MÁXIMO, 2010).

\section{A mobilidade e a interação nas cidades}

A constituição das cidades se deu por diferentes formas de mobilidade, como redes de transporte, de matéria e corpos em movimento, redes de comunicação - difundindo informações sobre os mais diversos formatos: cartas, telégrafo, telefone, televisão, rádio, internet - e mobilidade dos fluxos financeiros (comércio). Lemos (2007) explica que existem também os processos midiáticos que lhe são correlatos e estruturantes, como o jornalismo e as mídias audiovisuais, que operam com o fluxo, troca, deslocamento, desenraizamento e desterritorializações (das relações sociais, das informações e dos territórios). As cidades se desenvolvem como sociedades em redes físicas, simbólicas, culturais, políticas, imaginárias, econômicas. A particularidade contemporânea é a hegemonia de um conjunto de redes que passam a integrar as diversas redes que constituem o espaço urbano e as diversas formas de vínculo social que daí emerge. 0 processo de complexificação das redes continua com as metrópoles cibernéticas contemporâneas, que podem ser chamadas de "cibercidades" (Lemos, 2007), cidades onde as infraestruturas de comunicação e informação já são uma realidade e as práticas daí advindas formam uma nova urbanidade.

A mobilidade social, as relações com o espaço urbano e as formas comunicacionais passam por transformações importantes na atual fase da sociedade da informação. 0 desenvolvimento dos meios de comunicação se dá na própria dinâmica da industrialização e da urbanização da era 
moderna. As mídias reconfiguram os espaços urbanos, os subúrbios, os centros, dinamizam o transporte público e tornam mais complexo esse organismo-rede que são as cidades. Mobilidade e cidade são indissociáveis. Essa relação é uma constante, mas novas dimensões emergem com as novas tecnologias digitais (LEMOS, 2007, p.122)

Dentre as tecnologias móveis, o telefone celular tem sido o dispositivo maior da convergência tecnológica e também de constituição de relações sociais por contato imediato, seja através de voz, SMS, fotos ou vídeos (LEMOS, 2007, p. 131), em aplicativos desenvolvidos com funcionalidades específicas, a exemplo dos softwares que são instalados em computadores normais, de mesa. Dentro do paradigma moderno da mobilidade, ninguém precisará de um computador, por si só, para usar software. Tudo que você precisa será algo com um teclado, uma tela, e um navegador - browser (GRAHAM, 2010, p. 57).

Trata-se então de uma nova forma de mobilidade: a mobilidade por territórios informacionais, que altera e modifica a mobilidade pelos espaços físicos da cidade, como a possibilidade de acesso, produção e circulação de informação em tempo real. Por exemplo, o uso de celulares e sistemas de localização pode mudar a prática do uso do transporte urbano. Com um telefone celular, o usuário pode se informar, em tempo real, sobre o horário da passagem de um ônibus, criando novas dinâmicas de movimento no espaço físico (LEMOS, 2007, p. 130). Este poderoso cenário composto por dispositivos móveis acessando dados e software nas nuvens, faz com que o ponto de parada nas cidades contemporâneas sejam geralmente cafeterias ou qualquer lugar com zona de conexão sem fio ao ciberespaço no espaço urbano público (LEMOS, 2007). As pessoas trabalham e vivem de acordo com a oferta de conexão wireless, munidos de tecnologias sem fio como laptops, tablets e smartphones, fisicamente deslocando-se entre pontos para, eletronicamente, poder passear pelo ciberespaço.

No começo do século XX essa desterritorialização comunicacional ocorria pelos meios de massa: jornais, rádio, TV, revistas, e pelos meios interpessoais: correio e telefone. Hoje, os territórios informacionais (agora digitais) estão em expansão, utilizando ferramentas ubíquas e permitindo uma mobilidade informacional (emissão e recepção de informação) acoplada a uma mobilidade pelo espaço urbano. Essa nova mobilidade informacional pode permitir uma nova maneira de compreender, dar sentido e criar vivências no espaço das cidades contemporâneas (LEMOS, 2007).

\section{Ciberespaço e identidade contemporânea}

Máximo (2010) traz a acepção primeira da palavra "pessoa" que quer dizer máscara, reconhecendo o fato de que, mais ou menos conscientemente, o humano está sempre representando um papel e é nesses papéis que nos conhecemos uns aos outros e que conhecemos nós mesmos. Na contemporaneidade se constitui a evanescência do indivíduo e a reapropriação da pessoa: no lugar de identidades 
estáveis, o sujeito atualmente desfruta de uma série de identificações, desempenha vários papéis em cada um dos grupos, das tribos às quais se associa (MÁXIMO, 2010 , p. 40). Pode-se dizer que os cidadãos contemporêanos são hoje mais propensos à interação social justamente pela possibilidade de assumir diferentes papéis em diferentes locais, em diferentes momentos.

A intensificação da vida psíquica gerada nas grandes cidades em decorrência da rápida convergência de imagens súbitas, descontínuas e em constante mudança, sustenta a especificidade das individualidades metropolitanas em relação à vida rural, e para preservar a vida subjetiva dessa intensa diferenciação e da velocidade da vida metropolitana, o indivíduo desenvolve significativamente a intelectualidade, submetendo-se a uma crescente conscientização; por um lado os indivíduos nunca se viram tão livres para circular e se associarem em diferentes relações e grupos sociais, por outro lado eles são constantemente levados a buscar suas individualidades (MÁXIMO, 2010). Sibilia (2008) apresenta a valorização do próprio eu propiciada através da visibilidade e aceitação na sociedade em forma de superexposição. A web possibilitou também a criação de um mundo imaginário onde se torna possível cada indivíduo criar sua própria personalidade e a maneira como quer ser visto pelos demais.

Umas das razões para esta preservação e autonomia do indivíduo são os próprios dispositivos móveis e a sua infraestrutura de rede (CASTELLS, 2007). Por ser uma estrutura interconectada e aberta, a rede permite que seus usuários sejam reconhecidos individualmente pelas suas capacidades, os utilizadores deixam de ser simples usuários e são geradores de conteúdo e formadores de opinião - e da mídia pós-massiva. Na cidade contemporânea desenvolve-se uma relação estreita entre mídias com funções massivas (o impresso, o rádio e a TV), e as mídias digitais com novas funções (internet, e suas diversas ferramentas como blogs, wikis, podcasts, redes P2P, softwares sociais, e os telefones celulares com múltiplas funções). Se as cidades da era industrial constituem sua urbanidade a partir do papel social e político das mídias de massa, as cidades contemporâneas estão constituindo sua urbanidade a partir de uma interação intensa entre mídias de função massiva e as novas mídias, ou mídias pós-massivas, controladas pelo novo usuário-cidadão (LEMOS, 2007).

\section{Interação com as cidades}

Nas interações sociais agimos com base na percepção que fazemos das pessoas e situações, elaboramos ideias sobre o que é esperado de nós e sobre os valores, crenças e atitudes que se aplicam às situações interativas nas quais nos envolvemos (MÁXIMO, 2010). No momento atual, da mobilidade e das redes sem fio, estamos imersos em uma nova relação com o tempo, com o espaço e com os diversos territórios. A sensação, na globalização atual, é de perdas de fronteiras, de desterritorialização, mas também de novas territorializações (LEMOS, 2007). 
Antigamente, tínhamos fluxos centralizados de informação, com o controle editorial do pólo da emissão tomado por grandes empresas em competição entre si, financiadas pela publicidade. As mídias e as funções massivas tinham um papel social e político mais importante na formação do público e da opinião pública, pois eram dirigidas para a massa, pessoas que não se conhecem, que não estão juntas espacialmente e com pouca possibilidade de interagir (LEMOS, 2007). 0 modelo ainda existe, mas dá lugar para as mídias de função pós-massiva, que funcionam a partir de redes em que qualquer um pode produzir informação. Experiências na internet com blogs, gravadoras e músicos, softwares livres, podcasting, wikis etc., mostram o potencial das mídias de função pós-massivas: mais do que informativas, as mídias pós-massivas criam processos mais comunicativos, pela troca bidirecional de mensagens e informações e insistem em processos de conversação, de interações, de comunicação, em seu sentido mais nobre, tendo aí uma importante dimensão política (LEMOS, 2007).

Eram raras as formas de emissão e circulação de informação nas cidades da mídia de massa (circulavam fanzines, criavam-se rádios piratas, mas com limitações claras de acesso e de produção), eram ainda mais raras as possibilidades de emissão e circulação de informação pelo indivíduo em movimento. Os cidadãos podiam receber informações massivas, mas tinham dificuldade em produzir e enviar informações. As formas de comunicação interpessoal estavam limitadas ao confinamento (casa, carro, escritório, fábrica), ou a aparelhos públicos (orelhões) ou rádio amador que já refletiam um desejo de uma comunicação instantânea, móvel e ubíqua. Na maioria dos casos, o acesso à informação acontecia por dispositivos (TV, rádio) em espaços privados, com exceção do meio impresso, que permite a leitura em movimento, como os jornais e revistas, e do rádio, que permite a portabilidade e 0 acesso em movimento (LEMOS, 2007).

0 desenvolvimento da computação móvel e tecnologias sem fio (laptops, celulares, smartphones, tablets) estabelece um ambiente generalizado de conexão que envolvem 0 usuário em plena mobilidade. As cidades estão se constituindo ambientes generalizados de acesso pessoal e móvel à informação, constituindo um território informacional. Cria-se nas cidades contemporâneas zonas de controle de emissão e recepção de informação digital do indivíduo, em mobilidade e no espaço público, potencializando novas práticas sociais: contato pelo tempo real e o acesso informacional, banalização das relações interpessoais, formas novas de reforço identitário e social, e novos tipos de auto-exposição (LEMOS, 2007, p. 128). As cidades atuais tornam-se máquinas de comunicar a partir de novas formas de apropriação do espaço urbano - escrever e ler o espaço de forma eletrônica por funções de localização (com uso do GPS'), trazendo novas dimensões do uso e da criação de sentido nos espaços urbanos (LEMOS, 2007).

1 Global Positioning System - Sistema de Posicionamento Global 
As cibercidades podem ser pensadas como formas emergentes do urbano na era da informação. o desafio é criar maneiras efetivas de comunicação e de reapropriação do espaç̧o físico, reaquecer o espaço público, favorecer a apropriação social das novas tecnologias de comunicação e informação e fortalecer a democracia contemporânea. (LEMOS, 2007, p.123)

\section{Procedimentos metodológicos}

Os dispositivos móveis dão a uma considerável parte da população, a experiência de um computador pessoal. Esse seria o auge do individualismo da sociedade (não convém dizer necessariamente que são indivíduos isolados), em um modelo social que agrega interações específicas oriundas de comunidades online e off-line num formato híbrido de comunicação. Entretanto, esse individualismo e autonomia caminham, paralelamente, com responsabilidade de atender às novas exigências da economia (CASTELLS, 2007). Objetivando saber quem são os usuários dessa nova forma de comunicação e o que eles pensam a respeito da tecnologia móvel como ferramenta de interação com o ciberespaço e as cidades aplicou-se um questionário, o qual foi hospedado em uma plataforma on-line e enviado a setenta e três pessoas, dispersas geograficamente e pertencentes a uma faixa etária pré-determinada.

Tal questionário foi, então, enviado para moradores de cidades médias e grandes, com o objetivo de confirmar se, neste grupo, é grande o acesso ao ciberespaço em tempo real. Optou-se por considerar os indicadores de 2010 do IBGE', que classificam uma cidade como sendo de médio porte, quando possui de 10 a 500 mil habitantes e de grande porte quando sua população ultrapassa os 500 mil habitantes. A pesquisa foi aplicada a 73 pessoas na faixa etária entre 18 e 30 anos, propensas a responderem ao questionário e obteve-se um retorno de $100 \%$ entre os dias 20 e 24 de julho de 2012 , sendo que 9,6\% dos respondentes residem fora do Brasil, em cidades como Amsterdã, Hamburgo, Paris, Londres. As cidades brasileiras com maior percentual de resposta foram: Manaus (19,1\%), Florianópolis (16,4\%), Rio de Janeiro (12,3\%) e São Paulo (10,9\%).

A pesquisa não tinha pretensões de estar direcionada somente a usuário de dispositivos móveis, entretanto em sua totalidade os respondentes declararam possuir tais artefatos com acesso à redes $3 \mathrm{C}$ ou WiFi, 0 que lhes permitem interagir com 0 ciberespaço a partir de ambientes cotidianos, tais como suas próprias residências, locais de estudo (escolas e universidades) ou até mesmo em seus locais de trabaIho., e surpreendeu o percentual de respondentes que declararam fazerem uso de dispositivos móveis por mais de seis horas diárias: $63 \%$.

Dos respondentes, $93 \%$ declararam considerar a tecnologia como sendo instru-

2 ibge.gov.br/home/presidencia/noticias/noticia_visualiza.php?id_noticia=2019điid_pagina=1 
mento de integração social, enquanto apenas $7 \%$ consideram-na como sendo fator de isolamento social. Ao serem questionados quanto a contribuição da tecnologia para a melhoria de serviços (relacionados ao meio-ambiente, atendimento público e qualidade de vida) para a sociedade, $96 \%$ dos respondentes acreditam que as novas tecnologias podem sim contribuir para a melhoria destes serviços, promovendo a relação entre os cidadãos e as cidades onde vivem. Percebe-se então, que os jovens veem o desenvolvimento da mobilidade como um fator positivo e de impulso para a melhoria das relações sociais e integração de meios e serviços que facilitarão a vida dos cidadãos, através da eficiência, praticidade e conveniência.

Quanto à utilização, as pessoas se servem dos dispositivos móveis para entretenimento, atualização de informações, compartilhamento de atividades do cotidiano e organização de tarefas. A nova rede de comunicação leva à criação de comunidades instantaneamente, desequilibrando as estruturas tradicionais de comunicação e poder. A ação coletiva e a organização são facilitadas no ciberespaço e, além disso, como as notícias são distribuídas rapidamente, cada vez mais aparecerão antes nas redes sociais online do que na mídia tradicional, pela tendência apresentada na pesquisa apontada pela grande quantidade de pessoas conectadas em todo lugar e a todo o momento, e pelas atividades que desempenham nos dispositivos, como "Compartilhamento de atividades do cotidiano" e "Atualização constante de informação", com $63 \%$ e $64 \%$ dos sujeitos respondentes, respectivamente.

Ao responder a pergunta "Você acha que as novas tecnologias contribuem para a meIhoria de diferentes aspectos da sociedade?" $96 \%$ dos sujeitos foram otimistas e afirmaram que sim, o que levanta uma série de outras questões a serem solucionadas em pesquisas e projetos futuros: Como projetar e avaliar serviços conectados e sustentáveis e informações centradas no usuário para diversas necessidades dos moradores da cidade? Como envolver as comunidades da cidade para participar no desenvolvimento de inovações tecnológicas que irão melhorar o seu ambiente, sistemas de transporte e serviços locais? Quais interfaces inovadoras e interações são necessárias para incentivar a interação entre os cidadãos, empresas e governos? Como envolver as comunidades locais para entender como elas querem viver em suas cidades, envolvendo-os na concepção de inovações tecnológicas? Enfim, como criar e estender a tecnologia de computação para se conectar e enriquecer as vidas de cada pessoa na Terra?

\section{Conclusão}

Mais pessoas hoje usam novas e democráticas formas de se comunicar e informar, compartilhando sua localização, suas fotos, notícias. Mesmo que esses dados sejam principalmente pessoais (para amigos e conhecidos) elas podem também atingir públicos maiores. Informações aparentemente inofensivas compartilhadas no ciberespaço podem ter consequências inesperadas, especialmente se essas informações serão usadas para processos de participação pública. Torna-se impor- 
tante sensibilizar os usuários destes serviços a refletir sobre a informação que está sendo disponibilizada, através de interfaces e serviços honestos. A consciência das ações tomadas é uma necessidade de todos os usuários, de modo que devam ser capazes de determinar como e quando seus dados serão utilizados.

A difusão de smartphones, em rápido crescimento (Google et al., 2010), já se encontra num patamar elevado, e esta pesquisa também aponta nesta direção. A faixa da população sem dispositivos móveis pode se encaixar em uma faixa marginal de acesso à informação. Esta exclusão digital provavelmente vai mudar nos próximos anos, mas no momento atual só os "cidadãos móveis" (embora sejam maioria) são os potenciais participantes de quaisquer iniciativas que se utilizem dessas tecnologias. Também por isso, a interação com os dados do ciberespaço não podem se limitar ao público possuidor de dispositivos móveis, exigindo que existam outras relações com a internet, oferecendo, por exemplo, participações a partir de computadores de mesa.

0 ciberespaço se apresenta como um catalisador do fenômeno urbano, complexificando-o e fornecendo-lhe outras possibilidades para a diversificação social e fragmentação individual. É um espaço dividido entre as massas, tribos, microgrupos e individualidades, onde a vida social se organiza em um movimento sem fim. 0 advento da mobilidade oferece novas possibilidades para projetos culturais e de gestão, levando em conta que a redução dos limites espaciais e temporais permite a obtenção de informações a qualquer hora e em qualquer lugar. Isso significa que os cidadãos são potencialmente mais independentes para escolher quando, onde e como interagir com os outros e com as cidades. No grupo pesquisado confirmaram-se as tendências descritas na bibliografia da área, ou seja, a imersão dos cidadãosjovens, e das cidades grandes e médias no ciberespaço. Além de verificar o otimismo dos sujeitos participantes quanto aos benefícios das novas tecnologias.

Cidades são lugares onde as pessoas se encontram, trocam e interagem, unem fisicamente pessoas com diferentes interesses, experiências e conhecimentos, enquanto centros de cultura, desenvolvimento econômico e mudança social, portanto, devem-se cruzar novas fronteiras em matéria de aplicação das tecnologias de computação para o bem social, econômico e ambiental das cidades sendo este um salto evolutivo em termos de eficiência dos recursos, novos serviços e facilidade de viver, sendo estes os focos da sequência deste trabalho. Precisamos entender os desafios-chave das cidades e as oportunidades tecnológicas, pois o terreno está preparado e os habitantes acreditam e confiam no potencial das tecnologias em promover mudanças positivas. 


\section{Referências}

> CASTELLS, M. A Galáxia Internet: Reflexões sobre Internet, Negócios e Sociedade. Tradução de ESPANHA, R. Lisboa: Fundação Calouste Gulbenkian, 2007.

> GIL, Antônio Carlos. Métodos e técnicas de pesquisa social. 5. ed. - São Paulo: Atlas, 1999

> GOOGLE Inc, Otto Group, TNS Infratest, Trendbüro. Co Smart - 2012: Always in Touch, 2010. Disponível em: 〈http://www.ottogroup.com/media/docs/de/studien/ go_smart.pdf>. Acesso em: 30 jul. 2012.

> GRAHAM, Paul. Hackers it Painters: Big Ideas from the Computer Age. Farnham: O'Reilly, 2010.

> IBGE - Instituto Brasileiro de Geografia e Estatística. Disponível em: <http:// www.ibge.gov.br/home/presidencia/noticias/noticia_visualiza.php?id_ noticia=2019 tid_pagina=1>. Acesso em: 16 ago. 2012.

> LEMOS, André. Cidade e mobilidade: Telefones celulares, funções pós-massivas e territórios informacionais. In: MATRIZes n. 1., 2007.

> LÉVY, Pierre. 0 que é o virtual? São Paulo: Ed. 34, 1996.

> MÁXIM0, Maria Elisa. Da metrópole às redes sociotécnicas: a caminho de uma antropologia no ciberespaço. In: Antropologia no Ciberespaço. Theofilus Rifiotis ... [et al.], orgs. - Florianópolis: Editora da UFSC, 2010.

> SHIRKY, C. Here Comes Everybody: The Power of Organizing Without Organizations. New York: Penguin Press, 2008.

> SIBILIA, Paula. 0 Show do Eu: Intimidade como Espetáculo. Rio de Janeiro: Editora Nova Fronteira, 2008.

> SILVA, Leandro Libério da; SILVA, Armando Malheiro da; ZAIDAN, Fernando Hadad. Theoretical reflections of users info-communicational behaviors on social networks in internet. In: 8ć CONTECSI - International Conference on Information Systems and Technology Management, São Paulo. Anais do $8^{\circ}$ CONTECSI. São Paulo: USP, 2011.

Alice T. C. Pereira, possui graduação em Arquitetura e Urbanismo pela Universidade Federal do Rio Grande do Sul (1982), especialização em Habitação pela mesma Universidade (1983) e doutorado em Arquitetura - na Faculdade de Estudos Arquitetônicos da Universidade de Sheffield, Inglaterra (1992). Atualmente é professora da Universidade Federal de Santa Catarina. Tem experiência na área de Arquitetura e Urbanismo, com ênfase em CAD, atuando principalmente nos seguintes temas: arquitetura, ambiente virtual de aprendizagem, design, cad e hipermídia.

acybis@gmail.com 
Erik Silva Dos Santos, graduado em Design pela Universidade Federal do Amazonas e atualmente cursando o Mestrado em Design e Expressão Gráfica na Universidade Federal de Santa Catarina. Tem experiência em Design, atuando principalmente em Ergonomia, Ergodesign e Identidade Visual.

\section{dossantos.erik@gmail.com}

Eugenio A. D. Merino, possui graduação em Desenho Industrial pela Universidade Federal do Rio de Janeiro (1993), mestrado em Engenharia de Produção pela Universidade Federal de Santa Catarina (1996) e doutorado em Engenharia de Produção pela Universidade Federal de Santa Catarina (2000). Atualmente é professor associado II da Universidade Federal de Santa Catarina e coordena o Nucleo de Cestão de Design. Tem experiência na área de Design, com ênfase em Cestão de Design e na área de engenharia, especificamente com ergonomia, produto e processo. Participa dos programas de pós-graduaçao em Design e Engenharia de Produção ambos da UFSC. Faz parte do grupo de avaliadores do INEP/MEC e do Conselho Estadual de Educaçao de Santa Catarina na avaliação de cursos. É lider do grupo de pesquisa em gestao de design e pesquisador CNPq.

merino@cce.ufsc.br

Gilson Braviano, Licenciado em Matemática pela Universidade Federal de Santa Catarina (1987), mestre em Engenharia de Produção, na área de Pesquisa Operacional, pela Universidade Federal de Santa Catarina (1990) e doutor em Matemática Aplicada pela Université Joseph Fourier (Grenoble-França; 1995). Atualmente é professor associado II no Departamento de Expressão Gráfica da Universidade Federal de Santa Catarina, tendo atuado por cinco anos na Pró-Reitoria de Cultura e Extensão. As áreas de interesse em pesquisa envolvem os seguintes temas: geometria dinâmica, desenho geométrico, ambientes virtuais de aprendizagem, interatividade e estatísitca. Coordenou o Programa Conexões de Saberes na UFSC desde 2006 e atualmente é tutor do PET-Conexões de Saberes. É também presidente da ABEG - Associação Brasileira de Expressão Gráfica e ilntegra, desde 2006, no MEC, o Banco de Avalidores das Instituições de Ensino Superior Brasileiras.

gilson@cce.ufsc.br

Lucas Franco Colusso, graduado em Desenho Industrial-Habilitação Programação Visual pela Universidade Federal de Santa Maria, Brasil (2008). Atualmente cursa o mestrado em Design e Expressão Gráfica na Universidade Federal de Santa Catarina.

lucascolusso@gmail.com 